\title{
Suicide in the farming community: methods used and contact with health services
}

\author{
Nicholas Booth, Martin Briscoe, Roy Powell
}

\begin{abstract}
Farmers have a high rate of suicide $(1 \%$ of suicides in England and Wales). This study sought to test whether farmers would be less likely to have been in contact with primary or mental health services before death due to their reluctance to seek help. The study also sought to identify other characteristics that differentiated suicide among male farmers from other professional groups. A retrospective casecontrol design was used comparing male farmers with an age and sex matched control group. Cases were all members of the farming community within the Exeter Health District on whom suicide or open verdict had been recorded between 1979 and 1994. 63 Cases were identified and entered into the study. Controls were nonfarmers with the same verdict who were matched for age (5 year age bands) sex and social class. Farmers were significantly more likely to use firearms to kill themselves $(42 \%$ of farmers $v 11 \%$ controls). They were less likely to use a car exhaust or to die by poisoning (9\% farmers $v \mathbf{5 0 \%}$ controls). Farmers were significantly less likely to leave a suicide note ( $21 \%$ farmers $v 41 \%$ controls). There was no significant difference between farmers and controls for numbers in contact with their general practitioner or mental health services in the 3 months before death. There may be some differences in help seeking behaviour between farmers and the general population as over $30 \%$ of farmers presented with exclusively physical symptoms. General practitioners should consider depressive and suicidal intention in farmers presenting with physical problems. When depression is diagnosed consideration should be given to the temporary removal of firearms as the high rate of suicide in the farming community may be strongly influenced by access to means. (Occup Environ Med 2000;57:642-644)
\end{abstract}

Keywords: farmers; suicide

Farmers are one of the professional groups at highest risk of suicide in England and Wales, and account for about $1 \%$ of all suicides. The proportional mortality ratios for male farmers aged 16-64 were 205 in 1982-7 and 145 in 1988-92. For farmers and farmworkers combined these ratios fell to 167 and 129 respectively. ${ }^{1}$

Suicide among farmers is a particular cause of concern in Devon. For the years 1981-93 there were 62 suicides among farmers which was more than any other county in England and Wales. The mean annual rate of suicide among farmers over this period in the county was 38/100 000 and this represents a relative risk of 1.48 compared with the rest of England. ${ }^{2}$

Many factors have been proposed to account for this high rate including access to firearms, the prospect of unemployment, financial difficulties, and a sense of personal failure when this involved the loss of the family farm, a functional attitude to death, increased psychiatric morbidity, personality factors, isolation, lack of social support, lack of a personal meaning to life, and high levels of occupational stress. $^{2-4}$

Other factors may also be relevant. For example, there is some evidence that the use of organophosphates may have adverse effects on farmers. ${ }^{5}$ There is also evidence that rural decline and economic deprivation is a contributory factor in male suicide ${ }^{6}$ as well as the traditional belief that farmers do not like to complain or ask for help.

The hypothesis that this study sought to test was that farmers would be less likely to have been in contact with primary or mental health services before death, due to their reluctance to seek help. The study also sought to identify other characteristics that differentiated suicide among male farmers from other professional groups.

\section{Method}

A retrospective case-control design was used to compare male farmers with an age and sex matched control group. Cases were all members of the farming community within the Exeter Health District on whom suicide or open verdict had been recorded between 1979 and 1994.

Controls and subjects were taken from a database of 662 deaths where a suicide (E950959) or open (E980-989) verdict had been recorded on residents, aged 16 or over, of the former Exeter Health District between 1979 
and 1994. Of the 662 deaths, 70 (9.5\%) were members of the farming community (standard occupation classifications: 160 - farm managers; 900-farm workers; 901-agricultural machine operatives; 902-all other occupations in farming and related to it). Seven of these were women and they were excluded from the study. This resulted in 63 cases being identified and entered into the study. Controls were non-farmers with same verdict who were matched for age (5 year age bands), sex, and social class.

Information about the individual men was obtained from the coroner's inquest file and the general practitioner's (GP's) notes. Also, psychiatric and community mental health team records were obtained. This information included sociodemographic characteristics, contact with mental health and GP services, psychiatric history, diagnosis, and current treatments.

As well as this analysis, possible factors which might have contributed to the deaths in farmers were identified from records.

Statistical evaluation was performed with odds ratios. For some items there were considerable missing data due to the GP's records having been destroyed. Where this is the case the percentage of missing data is indicated and the percentages and statistical evaluation adjusted to only take into account the data collected.

\section{Results}

The table summarises the main findings.

DEMOGRAPHIC CHARACTERISTICS

The mean age of the 63 subjects was 53.8 years and the controls 54.6 years. Farmers were significantly more likely to have been born within the district and were more likely to be employed. There was no significant difference in marital status although more farmers were unmarried and single.
Within the study group there were 48 farm managers and 15 farm labourers. No significant differences were found between the two groups on any of the variables.

\section{CIRCUMSTANCES OF DEATH}

There was no significant difference in the verdict recorded or in the month or year of death. Farmers were significantly more likely to use firearms to kill themselves $(42 \%$ of farmers $v$ $11 \%$ controls). They were less likely to use a car exhaust or to die by poisoning ( $9 \%$ farmers $v 50 \%$ controls). Farmers were significantly less likely to leave a suicide note $(21 \%$ farmers v $41 \%$ controls).

CONTACT WITH GENERAL PRACTITIONERS Information was available on only $38(60 \%)$ farmers and $36(57 \%)$ controls due to the practice of destroying GPs' records within a few years of death. Of these there was no significant difference between farmers and controls for the numbers in contact with their GP in the week (26\% farmers $v 33 \%$ controls), month (53\% farmers $v 56 \%$ controls) or 3 months (35\% farmers $v 41 \%$ controls) before death. The information obtained from GPs' letters to coroners as well as the medical notes indicates that $31 \%$ of these last consultations by farmers were for exclusively physical reasons and $27 \%$ of consultations made reference to psychiatric difficulties.

PSYCHIATRIC CONTACT AND CHARACTERISTICS There were no significant differences in any of these characteristics, including: previous suicide attempts, numbers that were inpatients or day patients at the time of death, previous inpatient treatment, current or previous contact with outpatient or community mental health teams. Twenty one $(33 \%)$ farmers had a lifetime history of contact with psychiatric services and $14(23 \%)$ were in contact with mental health services at the time of death.

Table 1 Main findings of the study

\begin{tabular}{|c|c|c|c|c|c|c|}
\hline & \multicolumn{2}{|c|}{ Farmers $n(\%)$} & \multicolumn{2}{|c|}{ Controls $n(\%)$} & $O R$ & $95 \% C I$ \\
\hline \multicolumn{7}{|l|}{ General: } \\
\hline Age & \multicolumn{2}{|c|}{53.8} & \multicolumn{2}{|c|}{54.6} & & \\
\hline Born in Exeter district & & $(52)$ & 17 & (26) & 2.98 & 1.41 to 6.2 \\
\hline Employed & & $(60)$ & 25 & (41) & 2.16 & 1.06 to 4.41 \\
\hline Unemployed & 4 & (6) & 11 & (17) & 0.48 & 0.17 to 1.39 \\
\hline Retired & 21 & (33) & 27 & (43) & 0.67 & 0.32 to 1.37 \\
\hline Unmarried and single & 20 & (32) & 12 & (19) & 1.98 & 0.87 to 4.50 \\
\hline Open verdict & 5 & (8) & 2 & (3) & 2.63 & 0.49 to 14.09 \\
\hline Left a suicide note & 13 & (21) & 26 & (41) & 0.37 & 0.17 to 0.82 \\
\hline \multicolumn{7}{|l|}{ Cause of death: } \\
\hline Firearms & 27 & $(42)$ & 7 & (11) & 5.62 & 2.21 to 16.35 \\
\hline Car exhaust & 4 & (6) & 21 & (33) & 0.14 & 0.04 to 0.42 \\
\hline Poisoning & 2 & (3) & 11 & (17) & 0.15 & 0.03 to 0.73 \\
\hline Hanging & 24 & (38) & 16 & (25) & 1.97 & 0.91 to 4.26 \\
\hline Submersion & 1 & (2) & 1 & (2) & 1.00 & 0.06 to 16.35 \\
\hline Cutting & 1 & (2) & 2 & (3) & 0.44 & 0.04 to 5.57 \\
\hline Other & 5 & (8) & 6 & (9) & 0.82 & 0.36 to 1.72 \\
\hline \multicolumn{7}{|l|}{ Contact with medical services: } \\
\hline Saw GP in week before death & 10 & (26) & 12 & (33) & 0.80 & 0.32 to 2.02 \\
\hline Saw GP in month before death & 20 & (53) & 20 & (56) & 1.0 & 0.47 to 2.12 \\
\hline Saw GP in 3 months before death & 22 & (35) & 26 & (41) & 0.47 & 0.18 to 1.19 \\
\hline Previous suicide attempt & 8 & (13) & 15 & (24) & 1.55 & 0.42 to 5.79 \\
\hline Current inpatient or day patient & 6 & $(10)$ & 4 & (6) & 0.74 & 0.31 to 1.79 \\
\hline Previous inpatient & 11 & (17) & 14 & (22) & 0.77 & 0.28 to 2.10 \\
\hline Outpatient or CMHT client & 8 & (13) & 10 & (16) & 1.15 & 0.55 to 2.39 \\
\hline No previous mental health contact & 42 & (67) & 40 & (63) & 0.60 & 0.27 to 1.36 \\
\hline Antidepressants prescribed before death & 14 & (22) & 16 & (25) & 0.84 & 0.37 to 1.91 \\
\hline
\end{tabular}

$\mathrm{CMHT}=$ community mental health team. 
Both groups were just as likely to have been given a psychiatric diagnosis. Thirty three farmers $(52 \%)$ had evidence of a notable mental health problem. Depression was the most common diagnosis $(n=27,43 \%)$ followed by schizophrenia $(n=6,10 \%)$. Both groups were also equally likely to have been prescribed antidepressants or other psychotropic medication in the period before death.

\section{FACTORS CONTRIBUTING TO DEATH AMONG}

FARMERS

Twenty seven farmers (43\%) had a notable physical health problem and $20(32 \%)$ of these were chronic, 18 (29\%) had a work problem including recent loss of job, $11(17 \%)$ a relationship problem including separation, seven $(11 \%)$ a family problem, five $(8 \%)$ a recent bereavement, and four $(6 \%)$ financial problems. It was not possible to identify contributory factors in four $(6 \%)$ cases.

\section{Discussion}

In keeping with previous work this study found that farmers were more likely to kill themselves with a firearm whereas controls were more likely to use car exhausts or poisoning. It has been suggested that the availability of particular methods of suicide can affect the suicide rate $^{7}$ and that this would be particularly relevant to farmers who have ready access to firearms. There is, however, evidence that reducing access to firearms does not lead to a decrease in suicide rates in itself, but that it decreases the probability that this would be the chosen method. ${ }^{8}$ It is possible that farmers by having easy access to guns increase their risk of carrying out and dying from an impulsive suicidal act. This may in part account for the finding that farmers were less likely to leave a suicide note. The removal of guns from farmers with known mental health problems may prevent some deaths.

Although the findings on contact with general practitioners should be treated with some caution due to missing data, the numbers of subjects in contact with their general practitioner in the month before death are in line with the figures for people aged over 35 found by Vassilis. ${ }^{9}$ There may, nevertheless, be some differences in help seeking behaviour between farmers and the general population as over $30 \%$ of farmers presented with exclusively physical symptoms.

We were surprised that nearly a quarter of farmers were in contact with specialist mental health services at the time of death and were just as likely to have been prescribed antidepressants, although it should be noted that an earlier paper with the same subjects found that inadequate doses of antidepressants were prescribed in many cases. ${ }^{10}$

In conclusion, the factor which differentiated farmers who killed themselves from others, in this study, was their mode of death. Our findings do not support the hypothesis that farmers are less likely to seek help from their GP or mental health services although it may be that these services are not oriented to the needs of the farming community or the style of presentation, given that over $30 \%$ of farmers presented with exclusively physical symptoms. General practitioners should consider depressive and suicidal intention in farmers presenting with physical problems. When depression is diagnosed consideration should be given to the temporary removal of firearms as the high rate of suicide in the farming community may be strongly influenced by access to means.

We are indebted to HM Coroners for Exeter and North Devon for assisting us with the project.

1 Kelly S, Charlton J, Jenkins R. Suicide deaths in England and Wales, 1982-92: The contribution of occupation and geography. Popul Trends 1995;80:16-25.

2 Hawton K, Simkin S, Malmberg A, et al. Suicide and stress in farmers. London: The Stationery Office, 1998.

3 Gallagher AG, Sheehy NP. Suicide in rural communities. fournal of Community and Applied Social Psychology 1994;4:

4 Walker JL, Walker LJ. Self reported stress symptoms in farmers. f Clin Psychol 1988;44:10-16.

farmers. F Clin Psychol 1988;44:10-16.
5 Davies DR. Organophosphates, affective disorders and Davies DR. Organophosphates, affective disorders and
sucide. Fournal of Nutrition and Environmental Medicine 1995;5:367-74

6 Saunderson TR, Langford IH. A study of the geographical distribution of suicide rates in England and Wales 1989-92 using empirical Bayes estimates. Soc Sci Med 1996;43:489502 .

7 Clerk RV, Lester D. Suicide: closing the exits. New York: Springer Verlag, 1989

8 Leenaars AA, Lester D. The impact of gun control on suicide: studies from Canada. Archives of Suicide Research 1996;4:25-40

9 Vassilas C, Recent studies of contacts with services prior to suicide. In: Jenkins R, Griffiths S, Wylie I, et al, eds. The prevention of suicide. London: The Stationery Office, 1994.

prevention of suicide. London: The Stationery Office, 1994.
10 Boer H, Booth N, Russell D, et al. Antidepressant prescribing prior to suicide: role of doctors. Psychiatric Bulletin 1996;20:282-4. 